\title{
Experimental Studies on SiC and Rice Husk Ash Reinforced Al Alloy Composite
}

\author{
Y. M. Shivaprakash ${ }^{1 *}$, Anunoy Sarkar ${ }^{1}$, Sunit Jha ${ }^{1}$, Muktesh Singh ${ }^{1}$ and Shachin Bangera ${ }^{1}$ \\ ${ }^{1}$ Department of Mechanical and Manufacturing Engineering, Manipal Institute of Technology, \\ Manipal Academy of Higher Education, Manipal-576 104, Karnataka, India.
}

\begin{abstract}
In this research work Aluminium alloy with $\mathrm{Cu}(4.5 \%)$ as the major alloying element is used as the matrix in which $\mathrm{SiC}$ and Rice Husk Ash (RHA) are dispersed to develop a hybrid composite. The dispersion is done by the motorized stir casting arrangement. The composite is fabricated by varying the proportions of the reinforcements in the base alloy. The composite specimens were tested for density changes, hardness and the wear. The microstructure images showed a uniform dispersion of the reinforcements in the matrix and this resulted in higher strength to weight ratio. The increase in strength of the composite is probably attributed to the increase in the dislocation density. Also, the abrasive wear resistance of the produced composite is found to be superior as compared to the matrix alloy because of the hard-ceramic particles in the reinforcements.
\end{abstract}

\section{Introduction}

The research findings are required to meet the demands of industry maintaining the necessary property of materials and efficiency and cost saving in production. In meeting this requirement, a certain trend has been followed, the materials currently been utilized is tried for enhancement through known approaches of alloy blending, heat treatment, grain refinements, and the like. After the saturation, because of economic restrictions, difficulty in mass producing, or further enhancement is not possible so other line of approach emerged in further improving the properties or reducing cost and improving efficiency [1]. Among MMCs, Al-alloy-based composites were always extensively considered for research. Parallel areas of research had then emerged but after about two decades of research in various disciplines to further enhance the properties to satisfy the everincreasing demand of the engineering sector, composites took a lead compared to the other processes when the cost and ease of fabrication were compared [2]. The other methods changed track and chose for themselves different areas of application and Al-based metal matrix composites remained as the most potential candidate to be researched on for making engineering components viable.

Worldwide research in Aluminum MMCs (AMMCs) established beyond doubt the advantages of Al-based metal matrix composites over the base alloy in the laboratory scale.

\footnotetext{
* Corresponding author: prakash.ym@manipal.edu
} 
With time, the demands moved ahead and engineering components were demanded from AMMCs [3]. It can be easily concluded from the different results published from across the globe for two decades in AMMCs that the end use needs to be kept in mind before adopting a material and a process of fabrication. This is because the cost factors, ease of fabrication, shape, size, distribution, wettability between matrix alloy and second phase all must be considered for making a final choice depending on the component selected, mainly its working conditions for the engineering component to be fabricated.

In the past decade as research continued in this area yet the outcomes got were a just confirmation of the earlier obtained results, and a plateau in the possible enhancements has been reached [4]. Also attempts are being made to make engineering components from the AMMCs but still there is no mass utility of these composites. Some areas where research is still needed before these versatile materials see the light of the day as engineering components include machining, joining, repeatability of properties on mass production, and effect of secondary processing [5]. The difficulty in meeting the industry's demand can be easily seen from the lesser number of research publications in the last few years and old researchers were finding it difficult to answer questions related to the engineering potential of these composites. The material with better property needs to be converted to a component with better properties than presently available and here lies the challenge, like (i) cast AMMCs will seldom find use as engineering components, (ii) advantages accrued in cast composites do not always hold good when processed, (iii) only selected alloying elements can withstand the rigors and give meaningful results [6].

To date, the literature at least does not show a very promising picture regarding availability of engineering components been used which are made from AMMCs. However, a few components that have seen the light of the day from AMMCs include Swash plate, tennis racket, transfer bench, foot rest, and a few automobile components like brake drum, casings, head light combos, mining equipment, and a few components for structural applications, with an intention to replace either cast iron products or Al-alloy products presently used especially aimed at weight reduction, strength, stiffness, and energy efficiency [7]. The aerospace industries, automobile and railway sectors are keenly observing the composite research development.

The enormous amount of research and development that has gone into Al-based MMCs of every possible alloy with different reinforcements establishing beyond doubt the usefulness of making composites but a choice has to be made with both the base alloy selection and reinforcement size and volume percentage for making engineering components. Another point is that all engineering components will undergo some wear and damage related degradation with use even in an otherwise non-wear environment. The Al$\mathrm{Cu}$ and $\mathrm{Al}-\mathrm{Zn}$-based alloys are commonly used for making engineering components used in environments like those mentioned above.

Earlier work on Al-Cu-based composites show that these materials have been broadly investigated both in terms of knowing the mechanism of formation and properties assessment of composites, the main reinforcements being $\mathrm{SiC}$ and $\mathrm{Al}_{2} \mathrm{O}_{3}$. Researches with variable quantity of dispersions have been done. The Al-Cu-based MMCs have been evaluated for their tensile strength, hardness and abrasive wear properties and in most cases, have reported improvement in the hardness and strength of composites over the control alloy [8]. But, the amount of enhancement relies on the test conditions and microstructure of the MMCs. MMCs with suitable reinforcements like $\mathrm{SiC}$ have been able to bring a reduction in the density of the composite as compared to the base alloy. A decrease in density and an increase in strength is a major factor in increasing the strength to weight ratio of the composites. Thus, MMCs have a large scope in the aerospace and automobile industries and it can very well be the most important material of these industries in the future [2]. 
In the present investigation, $\mathrm{SiC}$ and $\mathrm{RHA}$ are dispersed in $\mathrm{Al}$ alloy having $4.5 \% \mathrm{Cu}$ to produce the hybrid composite. Two types of composites were produced with one composite having $2 \% \mathrm{SiC}$ and $1 \% \mathrm{RHA}$ and the other with $4 \% \mathrm{SiC}$ and $1 \%$ RHA. The composites were then successively tested for the mechanical properties.

\section{Experimental Details}

\subsection{Materials Used}

\subsubsection{Rice Husk Ash(RHA)}

The Rice Husk Ash particles used were between 50-60 microns and are the reinforcements to disperse in the matrix alloy. The rice husk was burnt completely in the presence of air and the ash was collected 24 hours later. The ash was then conditioned by heating the ash at a temperature of $300^{\circ} \mathrm{C}$ for 90 minutes to reduce the carbonaceous and volatile constituents of the ash. The chemical components of the RHA used is presented in the Table 1.

Table 1. Chemical component of RHA reinforcement.

\begin{tabular}{|c|c|c|c|c|c|c|}
\hline Element & $\begin{array}{c}\text { Silicon } \\
\text { dioxide }\end{array}$ & Carbon & $\begin{array}{c}\text { Calcium } \\
\text { oxide }\end{array}$ & $\begin{array}{c}\text { Magnesium } \\
\text { oxide }\end{array}$ & $\begin{array}{c}\text { Potassium } \\
\text { oxide }\end{array}$ & Hematite \\
\hline \% wt. & 91.56 & 4.8 & 1.58 & 0.53 & 0.39 & 0.21 \\
\hline
\end{tabular}

\subsubsection{Silicon Carbide(SiC)}

The $\mathrm{SiC}$ used in the present work is basically a hard-refractory material with particle size less than 20 microns. SiC has excellent thermal conductivity, low thermal expansion and it displays a good thermal shock resistance.

\subsubsection{Aluminium Alloy}

It is used as a matrix to hold the reinforcements. The aluminium alloy for the present investigation mainly consists of copper ( $4.5 \% \mathrm{wt}$.) along with other elements as shown in the Table 2 .

Table 2. Chemical component of aluminium alloy matrix

\begin{tabular}{|c|c|c|c|c|c|c|c|c|c|c|c|}
\hline Element & $\mathbf{S i}$ & Mg & $\mathrm{Cu}$ & Mn & $\mathrm{Fe}$ & $\mathbf{N i}$ & $\mathbf{T i}$ & $\mathbf{Z n}$ & $\mathbf{P b}$ & Sn & Al \\
\hline \%wt. & $\tilde{o}$ & $\begin{array}{l}0 \\
0 \\
0 \\
0\end{array}$ & $\bar{r}$ & $\frac{m}{0}$ & $\begin{array}{l}\hat{\sigma} \\
0 \\
0\end{array}$ & $\stackrel{n}{0}$ & $\stackrel{m}{\frac{m}{0}}$ & $\stackrel{\infty}{=}$ & సి & $\underset{0}{\tilde{O}}$ & $\begin{array}{l}\tilde{v} \\
\widetilde{U}\end{array}$ \\
\hline
\end{tabular}

\subsection{Production of Composite}

The ingots of $\mathrm{Al}$ alloy were broken into pieces and $3 \mathrm{~kg}$ of it was weighed and loaded into the electrical resistance furnace of $6 \mathrm{~kW}$ capacity. The alloy that was charged into the graphite crucible is heated to $850^{\circ} \mathrm{C}$ till the entire charge in the crucible was melted. The furnace is brick insulated. The reinforcement particles (RHA and $\mathrm{SiC}$ ) were preheated by 
placing them on top of the cover of the furnace for one hour, before introducing them into the melt, so as to remove moisture. The moulds used for casting were made of cast iron. They are preheated to $500^{\circ} \mathrm{C}$ to obtain uniform solidification. The pre-heating was done using a kerosene fuel pump burner. After the molten metal was fully melted, degassing tablet (Hexachloro methane) was added to remove the slag, flux and gas in the molten metal. Scum Powder is also added along with the degassing tablet into the molten metal to remove the slag and flux.

A stirrer made up of HSS coated with ceramic powder was lowered into the melt slowly to stir the molten metal at a speed of $700 \mathrm{rpm}$. The speed of the stirrer was controlled by means of a regulator. The average grain size of $\mathrm{SiC}$ particles was 63 microns whereas RHA had a grain size of 210 microns. The preheated SiC/RHA particles were added into the molten metal at a constant rate during the stirring. Stirring was continued for 5-10 minutes even after the completion of particle feeding. The melt of $\mathrm{Al} / \mathrm{SiC}$ and $\mathrm{RHA}$ is then maintained at $850^{\circ} \mathrm{C}$ for 10 minutes without stirring and then poured into the moulds allowing for solidification successively. The details of specimen prepared are shown in Table 3.

Table 3. Specimens of composite prepared

\begin{tabular}{|c|c|c|c|}
\hline Specimen ID & RHA quantity & SiC quantity & $\begin{array}{c}\text { Al alloy } \\
\text { quantity(Kg) }\end{array}$ \\
\hline$\# 1$ & Nil & Nil & 3 \\
\hline$\# 2$ & 30 gm (1\% by wt.) & 60 gm (2\% by wt.) & 3 \\
\hline$\# 3$ & 30 gm (1\% by wt.) & 120 gm (4\% by wt.) & 3 \\
\hline
\end{tabular}

\subsection{Testing of Composite}

\subsubsection{Density Test}

The density variation of the composite with the increase in $\mathrm{SiC}$ content for the fixed RHA quantity are shown in the Table 4 and Figure 1 . The density is calculated by the direct measurement of the mass and the volume of specimens.

Table 4. Density of specimens

\begin{tabular}{|c|c|c|c|c|c|}
\hline $\begin{array}{c}\text { Height (h) } \\
\text { mm }\end{array}$ & $\begin{array}{c}\text { Diameter (d) } \\
\mathbf{m m}\end{array}$ & $\begin{array}{c}\text { Volume (V) } \\
\mathbf{m}^{3}\end{array}$ & $\begin{array}{c}\text { Mass (M) } \\
\text { gm }\end{array}$ & $\begin{array}{c}\text { Density ( } \rho) \\
\mathbf{k g} / \mathrm{m}^{3}\end{array}$ & $\begin{array}{l}\text { Average } \\
\text { Density } \\
\left(\mathrm{kg} / \mathrm{m}^{3}\right)\end{array}$ \\
\hline \multicolumn{6}{|l|}{ Specimen \#1 } \\
\hline 20.12 & 15.16 & $3.63 \times 10^{-6}$ & 9.507 & 2617.0 & \multirow{3}{*}{2622.77} \\
\hline 20.14 & 15.14 & $3.625 \times 10^{-6}$ & 9.508 & 2622.8 & \\
\hline 20.11 & 15.14 & $3.62 \times 10^{-6}$ & 9.508 & 2626.5 & \\
\hline \multicolumn{5}{|l|}{ Specimen \#2 } & \multirow{4}{*}{2576.10} \\
\hline 20.13 & 15.12 & $3.614 \times 10^{-6}$ & 9.315 & 2577.5 & \\
\hline 20.13 & 15.12 & $3.6126 \times 10^{-6}$ & 9.313 & 2577.9 & \\
\hline 20.17 & 15.12 & $3.6215 \times 10^{-6}$ & 9.314 & 2572.9 & \\
\hline \multicolumn{5}{|l|}{ Specimen \#3 } & \multirow{4}{*}{2545.03} \\
\hline 20.22 & 15.16 & $3.649 \times 10^{-6}$ & 9.341 & 2559.8 & \\
\hline 20.32 & 15.21 & $3.692 \times 10^{-6}$ & 9.341 & 2530.6 & \\
\hline 20.27 & 15.20 & $3.678 \times 10^{-6}$ & 9.341 & 2545.2 & \\
\hline
\end{tabular}




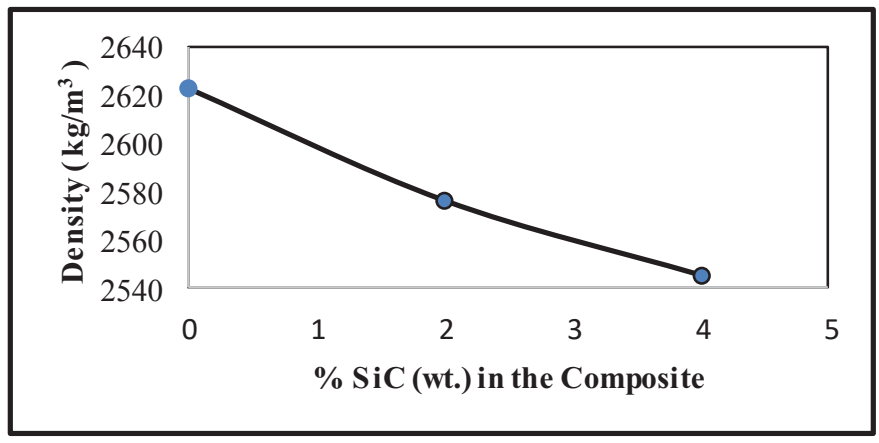

Fig. 1. Variation of density of specimens with quantity of $\mathrm{SiC}$

\subsubsection{Hardness Test}

Hardness test was carried out using a Brinell Hardness Tester with an applied load of $500 \mathrm{kgf}$. A ball indenter was used to make the indentation on the surface of the Specimen. The diameter of the indentation was then measured and the Brinell Hardness Number(BHN) was calculated from the formula:

$$
\mathrm{BHN}=\frac{2 P}{\pi D\left(D-\sqrt{D^{2}-d^{2}}\right)}
$$

where, $\mathrm{P}=$ load applied $=500 \mathrm{kgf}$

$\mathrm{D}=$ diameter of the indenter ball $=10 \mathrm{~mm}$

$\mathrm{d}=$ diameter of the indentation made on the specimen.

The results are tabulated in Table 5. And the comparison of hardness of specimens is shown in Figure 2.

Table 5. Hardness of specimens

\begin{tabular}{|c|c|c|c|c|}
\hline $\begin{array}{c}\text { Load (P) } \\
\text { Kgf }\end{array}$ & $\underset{\mathrm{mm}}{\text { Diameter (D) }}$ & $\underset{\mathrm{mm}}{\text { Diameter (d) }}$ & BHN & Average BHN \\
\hline \multicolumn{5}{|l|}{ Specimen \#1 } \\
\hline 500 & 10 & 3.5 & 50.32 & \multirow{3}{*}{46.74} \\
\hline 500 & 10 & 3.6 & 47.47 & \\
\hline 500 & 10 & 3.8 & 42.43 & \\
\hline \multicolumn{5}{|l|}{ Specimen \#2 } \\
\hline 500 & 10 & 3.5 & 50.32 & \multirow{3}{*}{49.85} \\
\hline 500 & 10 & 3.8 & 42.43 & \\
\hline 500 & 10 & 3.3 & 56.82 & \\
\hline \multicolumn{5}{|l|}{ Specimen \#3 } \\
\hline 500 & 10 & 3.4 & 53.43 & \multirow{3}{*}{54.76} \\
\hline 500 & 10 & 3.2 & 60.53 & \\
\hline 500 & 10 & 3.5 & 50.32 & \\
\hline
\end{tabular}




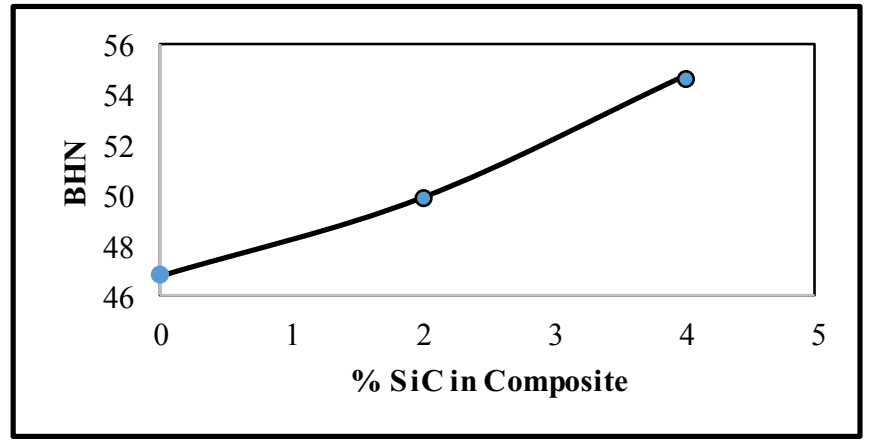

Fig. 2. Variation of BHN with increase in quantity of $\mathrm{SiC}$

\subsubsection{Wear Test}

To know the wear behaviour of unreinforced alloy and the composite specimens in dry conditions, testing was carried out on a pin-on-disc type wear and friction monitor [DUCOM, India make; Model: TR-201CL] attached with data capturing system (Figure 3) The wear tests were conducted as per ASTM G-99 standards.

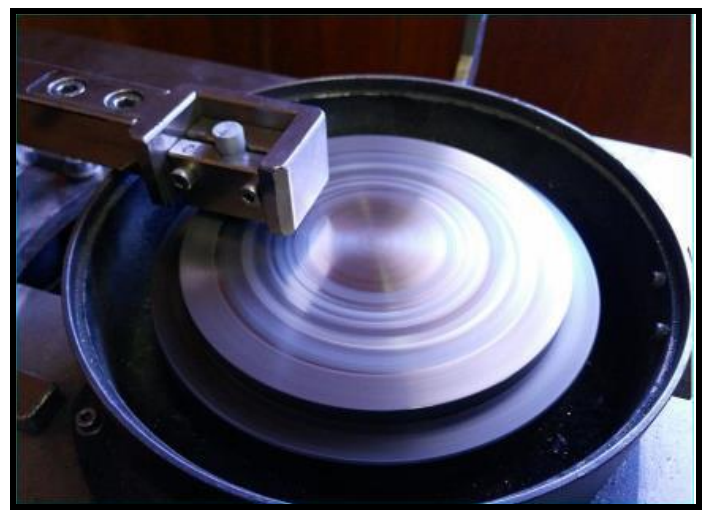

Fig. 3. Pin-On-Disc machine used for wear test

The test specimen used was a cylindrical pin ( $8 \mathrm{~mm}$ diameter and $30 \mathrm{~mm}$ length) which was held with its axis perpendicular to the surface of the disc, and one end of pin slid against the disc in a dry friction condition, under an axial load applied with a dead weight.

The test duration on each specimen was $10 \mathrm{~min}$. A constant rpm was maintained throughout the experiment. Mass loss was noted at the end of ten minutes and the weight was increased for the next trial. Also, the frictional force acting on the surface of contact was noted at regular intervals. This value was used to calculate the average coefficient of friction of that specimen at that weight.

\section{Coefficient of friction $(\mu)=$ Avg. Frictional Force in N/ Load applied in N}

The tabulated values as shown in the Table 6. This table show the wear test results for specimens. The comparison graph for the specimen is shown in Figure 4. The Variation of coefficient of friction, $\mu$ with Load applied at fixed rpm has been depicted in Figure 5. 
Table 6. Results of wear test on specimen

\begin{tabular}{|c|c|c|c|c|c|c|c|}
\hline Trial & $\begin{array}{l}\text { Speed } \\
(\mathrm{rpm})\end{array}$ & $\begin{array}{c}\text { Load } \\
\text { (N) }\end{array}$ & $\begin{array}{c}\text { Track } \\
\text { Diameter } \\
(\mathrm{mm})\end{array}$ & $\begin{array}{c}\text { Initial } \\
\text { mass } \\
\text { (gm) }\end{array}$ & $\begin{array}{l}\text { Final } \\
\text { mass } \\
(\mathrm{gm})\end{array}$ & $\begin{array}{c}\text { Friction } \\
\text { force, } F \\
\text { (N) }\end{array}$ & $\begin{array}{c}\text { Friction } \\
\text { Co-efficient, } \\
\mu\end{array}$ \\
\hline \multicolumn{8}{|c|}{ Specimen \#1 } \\
\hline 1 & \multirow{3}{*}{500} & 25 & \multirow{3}{*}{60} & 3.755 & 3.752 & 2.84 & 0.116 \\
\hline 2 & & 35 & & 3.752 & 3.747 & 7.06 & 0.206 \\
\hline 3 & & 45 & & 3.747 & 3.741 & 8.08 & 0.1 \\
\hline \multicolumn{8}{|c|}{ Specimen \#2 } \\
\hline 1 & \multirow{3}{*}{500} & 25 & \multirow{3}{*}{60} & 3.392 & 3.390 & 7.2 & 0.293 \\
\hline 2 & & 35 & & 3.386 & 3.383 & 12.7 & 0.369 \\
\hline 3 & & 45 & & 3.383 & 3.380 & 12.4 & 0.280 \\
\hline \multicolumn{8}{|c|}{ Specimen \#3 } \\
\hline 1 & \multirow{3}{*}{500} & 25 & \multirow{3}{*}{60} & 3.963 & 3.962 & 13.26 & 0.540 \\
\hline 2 & & 35 & & 3.962 & 3.960 & 14.68 & 0.427 \\
\hline 3 & & 45 & & 3.955 & 3.953 & 18.32 & 0.415 \\
\hline
\end{tabular}

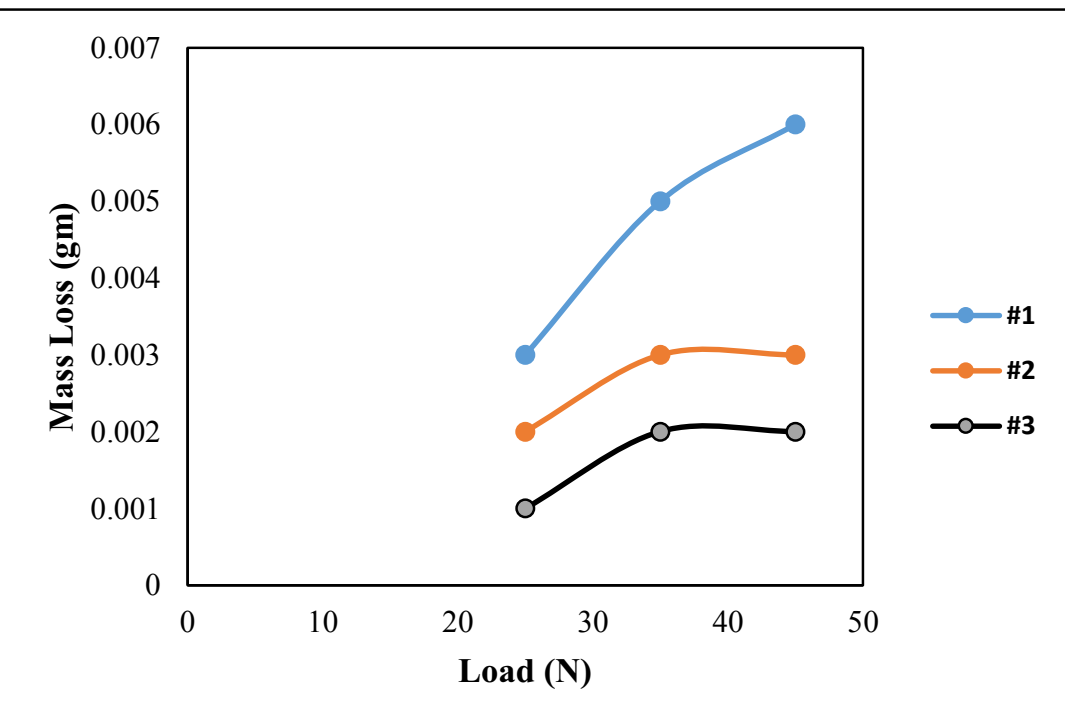

Fig. 4. Variation of mass loss with load at $500 \mathrm{rpm}$ 


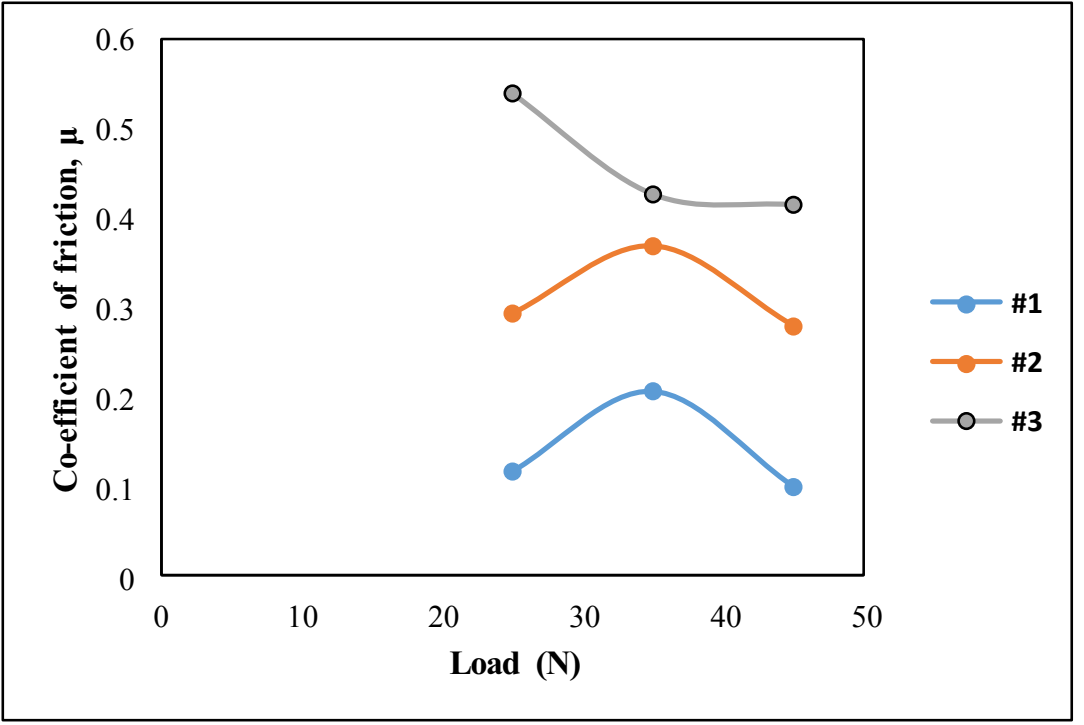

Fig. 5. Variation of Co-efficient of friction with load at $500 \mathrm{rpm}$

\section{Results and Discussion}

\subsection{Microstructure}

Figure 6 and 7 shows the optical micrographs of $\mathrm{Al}$ alloy and composite specimen \#2, respectively. A uniform distribution of reinforcement particulates throughout the matrix alloy can be observed from these images with a very minimal porosity level. Also, there is good bonding between the matrix and the reinforcement particulates which aids for a better load transfer from the matrix to dispersed particulates. There was no agglomeration of reinforcements since sufficient care was taken to prevent agglomeration by preheating the reinforcement particulates. The micrograph shown in Figure 6 is for the pure aluminum alloy. The black spots represent $\mathrm{CuAl}_{2}$ phase formed from the alloy of aluminum and copper in the matrix. They are mostly positioned along the grain boundary. Coarse grains suggest that the casting has been cooled slowly and at room temperature.

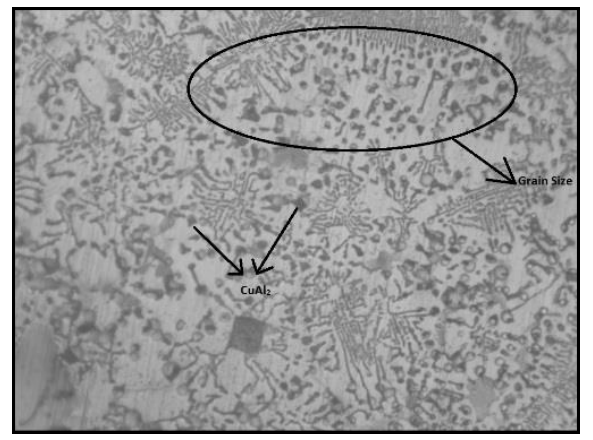

Fig. 6. Microstructure of Specimen \#1(500X) 
The micrograph shown in Figure 7 is for specimen \#2. The $\mathrm{SiC}$ is black spots with a prismatic shape and sharp corners along the grain boundary. Mainly the slow cooling might have resulted in uniaxial grains.

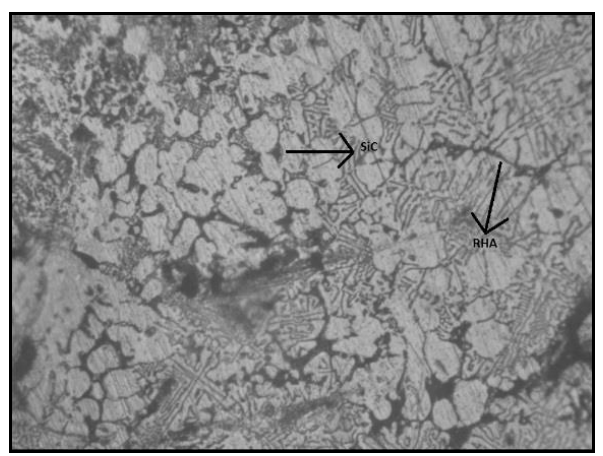

Fig. 7. Microstructure of Specimen \#1(500X)

\subsection{Density}

As depicted in Figure 1 the density of composite decreases as the quantity of $\mathrm{SiC}$ is increased for the fixed amount of RHA. This trend is attributed to the increase in the level of porosity for higher amount of dispersions. The entrapment of gas while stirring, release of hydrogen, the shrinkage during solidification and existence of air pockets in the molten alloy would also decrease the density of composite [9]. Certain amount of porous structure is unavoidable during the fabrication composites. The similar nature of variation in density is noticed by some researchers in their work [10-16]. There will be always a tendency to increase density of composites due to ceramic reinforcing particles $(\mathrm{SiC})$, but however there will be reduction in density because of dispersion of light weight reinforcements (RHA) in the hybrid composites.

\subsection{Hardness}

Hardness of the composite tends to increase with the addition of $\mathrm{SiC}$ over the alloy hardness. It may be because of hard $\mathrm{SiC}$ particles present in the matrix alloy. SiC particles along with $\mathrm{CuAl}_{2}$ precipitates along the grain boundary will create more resistance for dislocation motion, and thus increasing the opposing ability to plastic deformation leading to higher hardness.

\subsection{Wear}

Higher amount of $\mathrm{SiC}$ in composite reduces the mass loss as compared to alloy without reinforcement. This is probably due to the hard nature of $\mathrm{SiC}$ particles that are exposed on to the rubbing contact surface preventing the amount of mass loss. Also, the coefficient of friction $\mu$ remains mostly constant and is maximum for the specimen with the highest percentage of reinforcements. 


\section{Conclusions}

The conventional stir casting technique is successfully employed to produce the hybrid composite with uniform distribution of reinforcements. The density of the produced composite reduces as the quantity of reinforcement is increased. But the hardness increases with increase in $\mathrm{SiC}$ content. These particles along with $\mathrm{CuAl}_{2}$ phase has contributed in opposing the dislocation motion. The $\mathrm{SiC}$ has significantly reduced the mass loss of composites as compared to the bare alloy which is because of hard ceramic nature of $\mathrm{SiC}$ and due to the exposure of these at the rubbing surface. Since the developed composites have shown better mechanical properties as compared to Al alloy without reinforcements the on-hand composite is suggested for use in the wear resistant applications.

\section{References}

1. S.D. Prasad, R.A.Krishna, Int J Adv Sci Technol. 33, 51-8 (2011)

2. H. Zuhailawati, P. Samayamutthirian, C.H. Mohd Haizu, J Phys Sci. 18, 47-55 (2007)

3. T.Senthilvelan, S. Gopalakannan, S. Vishnuvarthan, K.Keerthivaran, Adv Mater Res. 622-23, 1295-9 (2012)

4. T.V.Christy, N.Murugan, S.Kumar, J of Miner Mater Char Eng. 9(10, 57-65 (2010)

5. K.V.Mahendra, K. Radha Krishna, J Com Mater. (44)8, 989-1005 (2010)

6. S.Balasivanandha Prabhu, L.Karunamoorthy, S.Kathiresan, B.Mohan, J Mater Proce Technol. 171, 268-273 (2006)

7. M.K.Surappa, Sadhana. 281\& 2, 319-34 (2003)

8. M.Adiamak, J Achevm Mater Manuf Eng.14, $43-7$ (2006)

9. Jaswinder Singh and Amit Chauhan, J Mater Res Tech. 5(2), 159-169 (2016)

10. D.B.Miracle, Compos Sci Technol. 65, 526-40 (2005)

11. K.K.Alanemea, B.O.Ademilua, M.O.Bodunrin, Tribol Ind. 35(1), 25-35 (2013)

12. O.A.Olugbenga, A.A.Akinwole, IntJ Eng Technol. 2(4),212-9 (2010)

13. K.K.Alaneme, I.B.Akintundea, P.A.Olubambib, T.M.Adewalec, J Mater Res Technol. 2(1), 60-7 (2013)

14. M.Boopathi, K.P.Arulshri, N.Iyandurai, J Appl Sci. 10(3), 219-29 (2013)

15. Z.Gnjidi,D.Boi, M.Mitkov, Mater Charact. 147, 129-38 (2001)

16. J.B.Rao, D.B.Rao,N.R.M.R.Bhargava, Int J Eng Sci Technol. 2(11), 50-9 (2010) 